\title{
VECTOR-STABILITY OF MULTIPLE VECTOR REFINABLE VECTORS
}

\author{
QINGYUE ZHANG
}

\begin{abstract}
The stability is an expected property for refinable vectors, which is widely considered in the study of refinement equations. There are two types of stability for refinable vectors. One is the ordinary-stability, the other is the vector-stability. The ordinary-stability considers the stability of entries of refinable vectors, but the vector-stability considers the stability of refinable vectors themselves where they are considered as elements of super Hilbert spaces. In this paper, we give a necessary and sufficient condition for refinable vectors to be vector-stable. Our results improve some known ones.
\end{abstract}

Mathematics subject classification (2010): 42C15, 42C40, 41A58.

Keywords and phrases: Super Hilbert spaces, refinement equation, vector-stability.

\section{REFERENCES}

[1] G. Bhatt, B. D. Johnson And E. Weber, Orthogonal wavelet frames and vector-valued wavelet transforms, Appl. Comput. Harmon. Anal., 23, 2 (2007), 215-234.

[2] S. Bildea, D. E. DutKay and G. Picioroaga, MRA super-wavelets, New York J. Math., 11, 6 (2005), 1-19.

[3] N. BI, B. HAN And Z. Shen, Componentwise polynomial solutions and distribution solutions of refinement equations, Appl. Comput. Harmon. Anal., 27, 1 (2009), 117-123.

[4] A. Cohen, I. Daubechies AND G. PlonkA, Regularity of refinable function vectors, J. Fourier Anal. Appl., 3, 3 (1997), 295-324.

[5] I. Daubechies AND J. C. LAGARIAs, Two-scale difference equations. I. Existence and global regularity of solutions, SIAM J. Math. Anal., 22, 5 (1991), 1388-1410.

[6] I. Daubechies, Ten lectures on wavelets, Society for Industrial Mathematics, New Jersey, 1992.

[7] G. Donovan, J. S. Geronimo, D. P. HARdin And P. R. MAssopust, Construction of orthogonal wavelets using fractal interpolation functions, SIAM J. Math. Anal., 27, 4 (1996), 1158-1192.

[8] T. N. T. Goodman And S. L. LeE, Wavelets of multiplicity $r$, Trans. Amer. Math. Soc., 342, 1 (1994), 307-324.

[9] Q. GU AND D. HAN, Super-wavelets and decomposable wavelet frames, J. Fourier Anal. Appl., 11, 6 (2005), 683-696.

[10] B. HAN AND R. Q. JiA, Quincunx fundamental refinable functions and quincunx biorthogonal wavelets, Math. Comp., 71, 237 (2002), 165-196.

[11] B. HAN AND R. Q. JIA, Multivariate refinement equations and convergence of subdivision schemes, SIAM J. Math. Anal., 29, 5 (1998), 1177-1199.

[12] C. Heil And D. Colella, Matrix refinement equations: existence and uniqueness, J. Fourier Anal. Appl., 2, 4 (1996), 363-378.

[13] T. A. Hogan, Stability and linear independence of the shifts of finitely many refinable functions, J. Fourier Anal. Appl., 3, 6 (1997), 757-774.

[14] T. A. Hogan, A note on matrix refinement equations, SIAM J. Math. Anal., 29, 4 (1998), 849-854.

[15] T. A. Hog AN, Stability and independence for multivariate refinable distributions, J. Approx. Theory, 98, 2 (1999), 248-270.

[16] R. Q. JIA AND C. A. MICCHELLI, Using the refinement equations for the construction of pre-wavelets II: Powers of two, Academic Press, New York, 1991.

[17] R. Q. JiA, Shift-invariant spaces on the real line, Pro. Amer. Math. Soc, 125, 3 (1997), 785-793. 
[18] R. Q. JiA, Q. JiAng AND Z. SHEN, Convergence of cascade algorithms associated with nonhomogeneous refinement equations, Proc. Amer. Math. Soc., 129, 2 (2001), 415-427.

[19] R. Q. JiA, Q. JiAng AND Z. SHEN, Distributional solutions of nonhomogeneous discrete and continuous refinement equations, SIAM J. Math. Anal., 32, 2 (2000), 420-434.

[20] R. Q. JIA AND C. A. MICCHELLI, On linear independence of integer translates of a finite number of functions, Proc. Edinburgh Math. Soc., 36, 1 (1992), 69-85.

[21] R. Q. JIA AND J. WANG, Stability and linear independence associated with wavelet decompositions, Proc. Amer. Math. Soc., 117, 4 (1993), 1115-1124.

[22] Q. JiAnG, Multivariate matrix refinable functions with arbitrary matrix dilation, Trans. Amer. Math. Soc., 351, 6 (1999), 2407-2438.

[23] Q. JiAng AND Z. SHEN, On existence and weak stability of matrix refinable functions, Constr. Approx., 15, 3 (1999), 337-353.

[24] W. LaWton, S. L. LeE AND Z. Shen, Stability and orthonormality of multivariate refinable functions, SIAM J. Math. Anal., 28, 4 (1997), 999-1014.

[25] S. Li AND J. YANG, Vector refinement equations with infinitely supported masks, J. Approx. Theory, 148, 2 (2007), 158-176.

[26] R. Long And D. Chen, Biorthogonal wavelet bases on $\mathbb{R}$, Appl. Comput. Harmon. Anal., 2, 3 (1995), 230-242.

[27] R. Long, W. Chen And S. Yuan, Wavelets generated by vector multiresolution analysis, Appl. Comput. Harmon. Anal., 4, 3 (1997), 317-350.

[28] A. Ron AND Z. SHEN, The Sobolev regularity of refinable functions functions, J. Approx. Theory, 106, 2 (2000), 185-225.

[29] Z. SHEN, Refinable function vectors, SIAM J. Math. Anal., 29, 1 (1998), 235-250.

[30] Q. Sun, Wiener's lemma for infinite matrices, Trans. Amer. Math. Soc., 359, 7 (2007), 3099-3123.

[31] E. WeBER, Orthogonal frames of translates, Appl. Comput. Harmon. Anal., 17, 1 (2004), 69-90.

[32] Q. ZHANG AND W. SUn, Vector-stability of refinable vectors, Appl. Anal., 92, 10 (2013), 2215-2228.

[33] Q. Zhang, Vector-stability of univariate refinable vectors, Numer. Func. Anal. Opt., 37, 7 (2016), 913-925. 